\title{
Enabling teachers to find their voices as leaders in the religion and worldviews community
}

\author{
Kathryn Wright ${ }^{1} \cdot$ Justine Ball ${ }^{2} \cdot$ Claire Clinton $^{3} \cdot$ Fiona Moss $^{4} \cdot$ Ed Pawson $^{5}$. \\ Sean Whittle
}

Accepted: 4 September 2021 / Published online: 22 October 2021

(c) The Author(s) under exclusive licence to Australian Catholic University 2021

\begin{abstract}
We present the process, collaborative management, and impact of a pilot leadership programme created to help teachers of Religion and Worldviews ( $\& \& W$ ) (We are using the phrase 'religion and worldviews' to reflect a change in approach advocated in the Commission on RE (2018). We use the abbreviation R\&W throughout. We acknowledge and accept that many are using the phrase 'religious education' or 'RE' to refer to the school subject.) find their voice as leaders. At the heart of the project's successful impact is a steering group which not only manages the programme, but models collaboration across the R\&W eco-system. Here we reflect as a team on the process of programme development particularly during the Covid-19 pandemic. We consider what we have learned individually and as a team, and how we each perceive the impact of the programme so far. We use a collective writing method, identifying key themes arising from the different perspectives and draw conclusions. This approach mirrors the way in which the team worked together reflecting the values of the joint funders such as integrity, openness, empowerment, and service. We conclude by offering this model as a way of working strategically across multiple diverse organisations.
\end{abstract}

Keywords Religion and worldviews · Leadership · Collaboration · Teacher-development

The Leadership Programme has been a fire-lighter to ignite the flames, to inspire me to move forward. Participant on the pilot programme, 2020.

\section{Introduction}

This may appear an unusual start to a journal paper, but we begin with the hottest day of the year in July 2019. It was on this day in the top room of the Oxford Playhouse that the embryonic leadership programme was scoped by a small gathering representing the diverse Religion and Worldviews (R\&W) community operating in the United Kingdom, some of this group went on to become members of the steering committee. The foundations and

Kathryn Wright

ceo@cstg.org.uk

Extended author information available on the last page of the article 
principles set out on this day were vital for the success of the programme, but also for the collaborative management of it.

Prior to this initial meeting, the group were invited to consider what types of leaders were needed by the $\mathrm{R} \& \mathrm{~W}$ community, and where the gaps in leadership were. In order to foster engagement and collaboration the main professional groupings working within the subject in England and wales were invited to participate, in particular AULRE, AREIAC, NASACRE, NATRE and the REC. ${ }^{1}$ The meeting was convened under the auspices of the charitable foundation Culham St Gabriel's Trust, under the directorship of Kathryn Wright. In recent years there had been other initiatives to develop leadership in the wider R\&W community. ${ }^{2}$ Kathryn also investigated other leadership programmes such as those run by the Chartered College of Teaching (https://chartered.college/chartered-teacher/) and the Historical Association's Chartered Teacher Programme (https://www.history.org.uk/secon dary/categories/CTHist) which have strong research foci. Kathryn also drew upon the discourse on theory of change. ${ }^{3}$

Culham St Gabriel's Trust has a history of funding projects which explore the relationship between research and practice in $\mathrm{R} \& \mathrm{~W}$. These currently include projects relating to curriculum, technology and the climate crisis. A vital element of the leadership programme was the importance and value of real world research; research rooted in classroom practice. The value of such research is well documented (see for example Baumfield et al., 2013).

In addition, to bring about systemic change at national level, as set out in the Commission on RE (2018), the group recognised the need to equip current and future leaders with appropriate skills, knowledge and expertise. The need for a well-respected leadership community that could work effectively together to transform the subject at national level was identified. At the heart of the pilot programme was a desire not only to equip leaders for systemic change, but to build a leadership community. The group felt that each of the main professional organisations brought particular areas of expertise which leaders could benefit from. Thus, there was a desire to work together strategically for the benefit of the whole subject community and a steering group with representatives (where possible) from these different organisations was created.

\section{Key features of the leadership programme}

The pilot programme was focused around four areas of leadership:

- Research engaged: The power of knowledge

- Curriculum engaged: The power of the subject

- Classroom engaged: The power of practice

\footnotetext{
1 These groups represent the religion and worldviews community in various ways in the United Kingdom. AULRE-Association of University Lecturers in Religion and Education, AREIAC-Association of Religious Education Inspectors Advisers and Consultants, NASACRE-The National Association of Standing Advisory Councils on Religious Education, NATRE-The National Association of Teachers of Religious Education, and the REC refers to the RE Council of England and Wales.

2 This included the leadership programme REvitalise (led by AREIAC and part-funded by Culham St Gabriel's Trust) and the related resources by Jan McGuire.

${ }^{3}$ For example, https://www.thinknpc.org/resource-hub/ten-steps/
} 


\section{Programme Outline}

The funded programme aims to develop leaders in the following four areas.

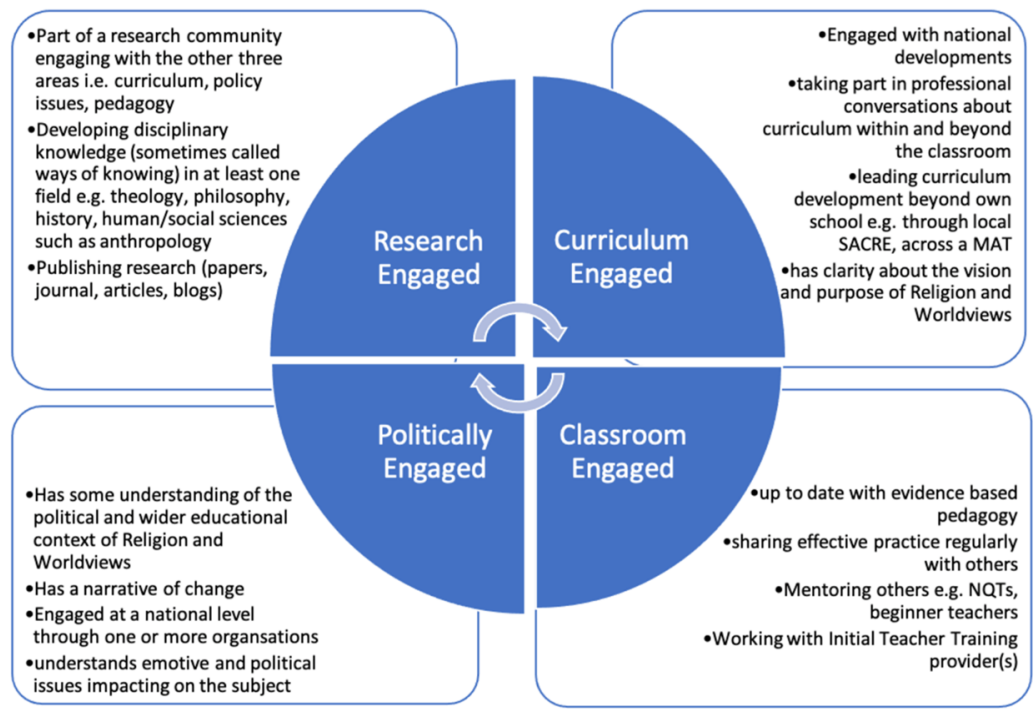

Fig. 1 Programme outline

\section{- Politically engaged: The power of influence}

The diagram (Fig. 1) outlines the different elements of each of the aspects. The programme endeavoured to enable teachers to become skilled in all four areas but acknowledged that each leader may have one or two areas of passion and expertise. The overarching aim was, and remains, a desire for the subject community to utilise the expertise of each leader to bring about systemic change.

The pilot programme ran two stages concurrently with a team of mentors supporting participants:

- Stage One, aimed at local or regional leaders who are beginning to work across more than one school. For example, leading the subject across a Multi-Academy Trust ${ }^{4}$ or supporting other schools in Federation ${ }^{5}$ and/or leading a local group or networking hub.

- Stage Two, for teachers or advisers who are likely to continue their specialism into senior leadership roles within or outside of their school situation.

Over the course of the pilot programme outcomes were refined and finalised. They were slightly different for each stage, but in summary, by the end of the programme participants were expected to have:

\footnotetext{
${ }^{4}$ In the England a Multi- Academy Trust is a group of schools in partnership with each other.

${ }^{5}$ In England, a Federation is a legal governance structure where between two and six schools share a single governing body.
} 
- Enhanced their regional or national profile within and beyond the R\&W community

- Increased confidence to lead R\&W regionally or nationally

- Increased understanding of the importance of research, pedagogy, curriculum and political dimensions in leading $\mathrm{R} \& \mathrm{~W}$ at a national level

- Increased their contribution to national events

- Increased confidence and authority to speak into the public space about R\&W e.g. through social media, events

- Increased forward-facing communication in one or more of the following areas of RE: pedagogy research, policy development, curriculum.

Defining the outcomes more clearly during the year enabled the steering group to measure the impact of the programme more effectively and focused the reporting of each participant at the end of the programme. The outputs for each participant varied, depending on the outcomes of their 360 audit and personal development plan. They included writing blogs, speaking at national conferences, writing for publication, rewriting school curricula, taking on new roles or significant positive career changes within the subject community and beginning Masters study. The outcomes and outputs were impacted by the Covid-19 pandemic, but for many this led to new and creative opportunities which were not anticipated in early 2020.

The programme has hugely increased both my confidence and knowledge; especially around research and pedagogy. As a result, I have read academic articles in a way that I have not since my university days! I have engaged with the history and story of RE and been able to have meetings with prominent academics in the field I am interested in. I feel this has broadened my thinking and understanding of religion and worldviews and given me ideas for my own teaching practice and in my wider role as an adviser and training others.

Participant on the Pilot Programme, 2020.

\section{Methodology: collaborative writing}

This article is presented in the style or genre of 'collaborative writing', which couch the reflections in a deliberately informal or colloquial voice. The leadership programme was a highly collaborative venture and this description of the programme and review of its impact seeks to embody and reflect this collaboration venture. The group felt that each of the main professional organisations brought particular areas of expertise which leaders could benefit from. Thus, there was a desire to work together strategically for the benefit of the whole subject community and a steering group with representatives (where possible) from these different organisations was created. Not only does this collective writing approach have a recent and positive precedent (see Orchard et al., 2012), but it also reflects the values central to this programme and would enable the distinct voices of the steering group to be heard. In order to facilitate both collaboration and allow each voice to be heard, each member of the steering team was invited to share themes and insights that struck them. Each 
was invited to write in first person and refer to others using first names. Kathryn Wright provided the opening introduction and drew together the conclusions. Our hope is that this article will provide a rich, personal and diverse commentary on the programme and the benefits of collaboration in furthering the cause of $\mathrm{R} \& \mathrm{~W}$.

\section{The lead consultant perspective ${ }^{6}$}

Martin Luther King Jr starts his famous speech 'I have a dream...' (King, 1968). I too had a dream over six years ago now when I wrote a paper to the AREIAC Executive (Association of Religious Education Inspectors, Advisers and Consultants) about mentoring and the need to mentor new leadership in our R\&W community. Over the last 30 years the usual ways teachers might develop greater levels of leadership in R\&W has dramatically changed, as education systems have been altered by government after government. I felt this meant the $\mathrm{R} \& \mathrm{~W}$ leadership community was in danger of not sharing the wealth of its combined knowledge and expertise with potential new leaders, or even worse there not being any new $\mathrm{R} \& \mathrm{~W}$ advisers.

For me the leadership programme pilot has provided a framework for everyone involved-mentees, mentors and the steering group to grow and develop. It may be because I have spent the last year doing my garden in lockdown, but plants need the right soil, environment (some like it sunny, some like shade), nutrients and support to flourish. I believe the strength of this programme comes from us meeting all the needs in different ways for each participant.

My strongly held belief in the value of mentoring is rooted in my own professional experience. As an early career teacher, Mrs Barnes, my head of humanities and Dr Bill Gent who mentored me when starting out as an advisor provided me with a secure framework in which I could grow and develop. Many others have come alongside me to feed, water, shield and support me across my career. I know I wouldn't have the knowledge and skill set without those people investing in me, helping me to grow.

We are all different, unique and what each of us needs to grow is unique too. The programme brings two people together-a simple and yet incredibly powerful connection. It gives them a programme and a support framework but they create the content, the shape of their focus and reflections. The mentor and mentee give each other room. In a rich environment of nurture each participant is empowered to decide what they want to gain from the process.

I want to say something about the power of developing me. As teachers we get appraised in schools and it is one way and monitoring. This is different, you get a relationship with an adult in a coaching relationship - they aren't monitoring you, it's about expanding you. Helping you to develop your voice, who you can be to the RE community. There is no space for this normally in our school setting. This allows you to grow and develop collaboratively.

Participant on the Pilot Programme, 2020.

I believe the programme is a smart use of time. This way of working ensures we get many returns from our seemingly small investment. Returning to my gardening metaphor,

${ }^{6}$ Claire Clinton, Director of RE and RSHE, Newham. 
it took me under five minutes to poke my peas and mangetout seeds into the ground, three months later they have grown up and now producing a crop. When I come home from work, I delight in going to the top of the garden to harvest them for our evening meal. We need this type of smart working in education and I believe with this programme we have shown impactful, measurable, developmental change in each participant's leadership path.

I am particularly grateful for the opportunities to connect with other participants in the Leadership Programme. I am left feeling we are part of a varied but supportive community and have made professional links with people I would probably not have had the opportunity to learn from. The great strength of this programme is how it supports all of the participants to both stretch themselves out of their comfort zone and to find their own niche. I am so grateful for the opportunities the mentoring team and the other participants have offered.

Participant on the Pilot Programme, 2020.

I have learnt so far in my role as the leader of the programme that firstly, having a strong methodology and foundations, alongside a diverse team are the most impactful and productive way to work. Secondly, that providing a structure for younger colleagues to find their $\mathrm{R} \& \mathrm{~W}$ voice is vital if we want our profession to be well served in the future. Thirdly, mixing professionals at different stages on their teacher/adviser journey is enriching for both parties-bringing people together in dialogue nourishes everyone involved. Finally, it has taught me that we must follow our passions and surround ourselves with those who are passionate about what we are if we want to develop, innovate and positively change the status quo.

\section{The steering group perspective ${ }^{7}$}

Anyone who knows me knows that I am a people person. I love bouncing ideas off others and am energised by the company of others. Perhaps curiously, the older I get the more I want to hear voices with different experiences and expertise; working together on the steering group provided this. There is also a burning desire within me to support and empower leaders to step into the $\mathrm{R} \& \mathrm{~W}$ community. This comes from the fact that this was so much easier for me to do when I started teaching in 1991. Within seven years of starting to teach I had found opportunities to work on an agreed syllabus conference, attend a 20 day subject knowledge and understanding (GEST - Grants for Education Support and Training) course, write RE materials for the local authority, become a member of what was then the PCFRE $^{8}$ (now NATRE) executive and undertake a Farmington Fellowship (Moss, 1998). As you might expect representing NATRE on the steering group for such an important project ticked both boxes I describe above.

In the original project conception the steering group were going to regularly meet together in person in London to guide the programme, put together material, recruit mentors and mentees and help to shape the programme in its initial pilot phase. As one might imagine there were only two face to face meetings one in a coffee shop and one in a hotel room selecting the first members of the programme. However, perhaps because of those

\footnotetext{
${ }^{7}$ Fiona Moss, National RE Adviser and Chief Executive of NATRE.

${ }^{8}$ Professional Council for RE.
} 
initial face to face meetings and also because of the close connections in the R\&W ecosystem working virtually with the steering group was energising, enlightening, sometimes thought provoking and driven by an important common cause.

It was essential that the steering group was a collaboration across the $\mathrm{R} \& \mathrm{~W}$ eco-system because we are empowering leaders who would need to be 'fed' from across the community and would gain in confidence to step outside their natural strengths. The varying perspectives from the different organisations represented on the steering group ensured that we had connections and expertise but also the confidence to ask hard questions of one another. It also felt right that each of the organisations offered someone to 'serve' as part of this future focused project. Talk of service of course sounds terribly 'worthy' but, as often in these situations, I got much more than I gave as part of the steering group.

The broad membership of the steering group allowed us to use our strengths and develop the programme in the pilot year; one example of this was Sean Whittle's idea of starting a reading group. He was able to use his expertise as both an academic (he is currently Vice-Chair of AULRE) and also as a teacher in order to nudge the mentees into in-depth study of academic papers (which included doctoral theses by Hannam (2016) and Wright (2017)). A key strength of the programme was its ability to gently support teachers to engage with research and to see its worth in the classroom and in leadership within the wider R\&W community.

Members of the steering group also took part in many aspects of the programme, acting as mentors and leading community of practice evenings. Acting as a mentor to a secondary school teacher felt an unusual thing to ask me to do as I have a primary school background. However, it actually encouraged me to reflect and support my mentee in new ways and also gave me a real insight to his role. The community of practice evenings, preparing and leading a discussion on a key paper in the area of religion and worldviews, was also fulfilling, encouraging me to challenge my own thinking as I prepared questions and then considered the ideas, opinions and questions of the mentees.

I'm sure the other members of the steering group find this ongoing project and working as a steering group as uplifting as I do; learning from one other, learning from mentors and mentees, collaborating across the R\&W ecosystem and supporting future leaders. I hope this steering group model will be one we can use in other projects too.

\section{The stage one tutor/mentor perspective ${ }^{9}$}

I am part of the steering group and was a mentor to one of the Stage One participants from the beginning of the programme in March 2020, as well as leading some of the community of practice sessions with all the Stage One mentees. The programme is best described as a journey for both myself and for the candidates and an important part of this journey was how candidates dealt with their own feelings of being a student and sometimes overcoming a feeling of inadequacy, especially in the role of a leader for others. Many people will recognise these feelings and its label as "imposter syndrome"; most of us will experience

\footnotetext{
9 Justine Ball, Hampshire Primary RE Inspector and Adviser,Co-Chair of AREIAC.
} 
this at some point in our lives. How we deal with it is a marker of success and it is this that I reflect on most here.

For part of my working life, I worked in Adult Education as a tutor for many years before becoming a primary school teacher and later the Hampshire Inspector/Adviser for Primary RE. In my years of tutoring adults, I observed that many of them, regardless of the learning programme, went through the same stages of motivation during their studies. Beginning with excitement and anticipation at the learning ahead often led to a real concern after two or three months about the amount of work ahead and the belief that they were not good enough for such a journey. It can take some people many months to battle through this and come out the other side to achieve success. For some, it does not happen at all and they do not continue with their studies or achieve what they know they are capable of. This journey can be typical, whatever the learning and often happens to those of us who feel less confident or may perhaps have too much going on in life at a particular time to thrive when extra challenge is given to us.

Sometimes, participants on the Stage One programme described that feeling to me too, calling it imposter syndrome and reflecting that after a glorious beginning they too realised shortly after starting that there was a large amount of work and new experiences to come and all of this within a time of a national pandemic. Some stated that they felt that others might do a better job or know more than them and this made them consider their worth in hoping to develop further as a $\mathrm{R} \& \mathrm{~W}$ leader. This is something that $\mathrm{I}$ have experienced myself and have regularly witnessed among adult students. Overcoming this more than any amount of learning is often the key to finishing your journey successfully.

Participants shared these feelings in one of our early sessions together. All agreed that this was not reality but a feeling that many people have. They agreed to work as a team to support one another, to keep going and to accept that there are times when everyone feels this way. The main way that the candidates dealt with this was by forming a supportive and encouraging community of practice within themselves and by discussing this with us as mentors where honest feelings were shared, everyone was listened to equally and all were treated with respect. Participants stated that by sharing these feelings and realising others felt exactly the same had a real effect on them and their perception of themselves as a leader. Their journey for the rest of their time together was transformative as they began to flourish, find their own voice and realise all were very capable leaders in their own right. They began their journey as teachers with a passion for their subject; they finished their journey as emerging leaders full of wisdom and the confidence that they had met their fears and overcome them.

These are the conversations and debates that I will remember from the Stage One journey and through this, deeper conversations about research, substantive knowledge and the curriculum emerged. My own mentee as an example of this journey managed to combine moving house, moving school, moving geographical location, lockdown, Covid in the family and studying all within the space of one year. Such a journey is extraordinary and the fact that my mentee made a complete success of these things is a credit to them and to the programme for providing the means to share and discuss these experiences while carrying on, one step at a time.

It has left me with vivid memories of the experiences of studying and mentoring through a national pandemic and sharing the emotions and experiences of this with a group of amazing mentees. Thank you to them all and I know that I will look forward to the second part of their journeys in the years to come. You have taught me well. 


\section{The stage two mentor perspective ${ }^{10}$}

I was really excited about the idea of becoming a mentor on the leadership programme. In particular, what attracted me was the idea of working with such an enthusiastic and talented set of emerging leaders in $\mathrm{R} \& \mathrm{~W}$, collaborating to explore some of the dimensions of what it means to be a well-rounded professional in R\&W. An AREIAC conference in July 2019, gave me an understanding of the aims of the REvitalise programme, and an insight into its impact: I had been blown away listening to the participants of the programme talking about their experience; their enthusiasm for the journey they had been on, their newly amplified connection with the subject and the way it had allowed them to think about strategic leadership in the subject were all really infectious!

At its heart, the leadership programme aims to help teachers flourish in their classroom practice, curriculum vision, political activism and research awareness. This really connects with my own interests for $\mathrm{R} \& \mathrm{~W}$. What I most enjoyed about my mentoring experience was having the opportunity to open up conversations leading to real growth and development in these areas. The aspect that participants seemed to feel most in need of developing was research awareness and engagment. This is, perhaps, not surprising, given that most teachers are focused on the delivery of their own curriculum: planning, preparing, teaching, marking. That's the day job, and it's full-on, even for teachers who are not full time. What few of us find enough energy for is deep reading and active research. These are luxuries. So, the way in which the programme was able to set up opportunities for mentees to engage in collaborative reading and to plan their own original research was an invaluable feature.

The first research reading project, skillfully led by Sean Whittle, took us deep into Pat Hannam's PhD thesis on Education in the Public Sphere (Hannam, 2016). Pat's evaluation of the unfolding story of $\mathrm{R} \& \mathrm{~W}$, with her analysis on the ideas from some of the leading figures in the subject, provided great material to help us consider where the subject has come from and how it continues to change. This was a great way to start, exploring a serious piece of academic writing which sets out a particular view of the history of RE in English schools. Our next reading assignment was to explore the report Worldviews in Religious Education (Cooling, Bowie, Panjwani, 2020). This inspired considerable discussion, with participants feeling that there was much material here to share with colleagues in staff professional development or in initital teacher education. Many felt that the approach sat well with the way they already teach $\mathrm{R} \& \mathrm{~W}$, representing a direction in which they believe the subject needs to evolve. One significant question which arose from the conversation was around whether a worldviews approach is too complex for younger learners (e.g. at Key Stage One). There was general agreement that this is not the case, but it will be important to see what research can be done in this area in the coming years. It was suggested that by introducing pupils to a set of technical vocabulary at an early age there is no reason why they cannot engage in complex discussions about a diversity of beliefs, setting a good platform for later understanding.

Perhaps the biggest impact of the programme was the outcomes from the participants' own engagement in research. Here is a sample of the stimulating lines of enquiry set up through this exercise: using hermeneutical tools to dig deep into passages of sacred scripture from diverse religious traditions; developing the use of vocabulary to enable pupils to engage in rich conversations about religious beliefs; exploring what a worldviews approach

${ }^{10}$ Ed Pawson, RE Adviser, South West England. 
to $\mathrm{R} \& \mathrm{~W}$ looks like in the primary classroom; engaging secondary students in a conversation about diverse attitudes towards sexuality through a worldviews lens; exploring a disciplinary approach to R\&W from early years to Key Stage Five.

Overall, my takeaway from this experience as a mentor on this programme has been immensely positive. Hearing the participants express how significantly it has impacted on their own understanding of what it means to be working in $\mathrm{R} \& \mathrm{~W}$ in a professional context has made it doubly valuable.

\section{The mentor and reading group facilitator perspective ${ }^{11}$}

In addition to being the AULRE representative on the Steering Committee, I was called upon to be a Stage Two mentor. As such I knew I would be working with a colleague who already had some involvement in the wider R\&W scene, beyond leading the subject at school level. I had the pleasure of working with someone who combined their teaching role as a primary teacher (as subject lead/co-ordinator) with being the part-time Advisor for an Anglican diocese. This allowed for an interesting dynamic because professionally I am secondary R\&W teacher who combines this role as an educational researcher (who specialises in Catholic education). A perennial problem, in my experience in the UK, is that primary school and secondary teachers do not spend anywhere near enough time in professional conversation. This means the opportunity to mentor a primary $\mathrm{R} \& \mathrm{~W}$ practitioner is one that I embraced as a golden opportunity. I enjoyed and gained from the experience of having regular dialogue with a primary colleague.

In terms of mentoring, my mentee wanted opportunities to develop his grasp and involvement in academic aspects of $\mathrm{R} \& \mathrm{~W}$. In the initial mentoring sessions exciting plans for offering short papers at AULRE's conference events were mooted. However, we had not factored in the unfolding events related to the Covid-19 pandemic and the ensuing lockdown(s). Our plans for real-life meetings quickly evaporated and the dawning reality that life, including academic conferences were to be postponed or eventually move to be on-line events, began to slowly sink in. Against this context I proposed to my mentee that we create a reading group with the intention of giving a careful reading to a number of academic texts that reviewed the history of Religious Education in England and Wales. Besides the practical advantages of convening an on-line reading group, there were several deeply academic reasons behind the choice of topic. First, in order to orientate my mentee into the academic debates in $\mathrm{R} \& \mathrm{~W}$ it is essential to help him navigate his way around their historical roots. Second, there are several emerging researchers who have written excellent academic accounts of the history of the subject in England. These historical narratives have their context in doctoral thesis and as such represent the cutting edge of academic work in the subject. Reading doctoral level work is not something that one typically comes across in routine life as an $\mathrm{R} \& \mathrm{~W}$ practitioner. It is a distinctive genre of academic writing. Opening it up to my mentee proved to be an apt way of engaging with more academic aspects of $\mathrm{R} \& \mathrm{~W}$. In practical terms the reading groups spanned over four sessions, meeting every other week. One of the unforeseen benefits of the lockdown is that many of the other Stage One and Stage Two mentees were also able to participate in the reading group. To assist with the discussion and reading, I identified questions designed to critically engage with

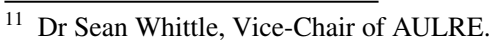


the text and identify the underlying arguments in the historical narrative. The discussions were engaging and thought provoking, and had the advantage of giving me further opportunities to work with my mentee. As an individual mentor, it was good to also engage with the other participants in the leadership group.

One of the ways I was able to support my mentee was through being a point of contact with many of the leading academic voices working in RE/R\&W in the UK. Being able to facilitate introductions and making these academics more accessible figures helped my mentee grow in confidence. Indeed, it was in witnessing to this that has been a particularly rewarding part of being a mentor.

\section{Conclusions}

What does it mean for participants on a leadership programme to flourish? Each of the personal reflections indicate a sense in which growth occurred for each participant within a hospitable and nurturing environment.

A recent report from a Culham St Gabriel's grant funded project emphasises the importance of creating hospitable spaces for researcher-teacher engagement (Baumfield et al., 2021). This project aimed to understand how teachers engage with research and how best to promote a 'bi-directional relationship' that draws upon the expertise of researchers and teachers. The project leaders aimed to gain a deeper understanding of the types of research, both subject specific or general educational research, that are used and the ways in which this is accessed, interpreted, and mediated by teachers of R\&W. A key finding of the project was that hospitable places need to be created in which dialogue between teachers and researchers can be fostered and relationships of trust developed. Teachers value professional learning communities where there is a strong sense of belonging, such as a community of practice. This leadership programme exemplified this approach.

Claire uses a gardening metaphor to talk about growth, as well as frames or structures of support to enable participants to thrive. Fiona emphasises the importance of togetherness, and the interconnectedness of the whole programme; drawing the R\&W eco-system together strategically to cultivate open conversations between and within the different groups. Justine uses a different metaphor of journey, but again highlights the ways in which participants overcame obstacles and challenges through encouragement and care. Ed uses growth and flourishing metaphors to describe the way in which teachers gained confidence to engage in research. Sean speaks of the power of professional in-depth conversation and helping teachers understand the historical and contextual dimensions of being part of the R\&W community. Throughout the reflections, the importance of personal relationship, coming alongside one another and mutual trust are stressed. This applied in each case not only to the participants, but also to the groups of mentors and the steering group. The expectations of the relationship between mentor and mentees were set out clearly at the start, so that a nourishing and supportive approach was cemented. This mirrored the open and transparent virtual space created by the diverse steering group, leading to a "virtual' ethos within the communities of practice themselves. As Fiona has indicated in her reflections, this form of steering group could be used for other initiatives to bring together diverse voices from across the $\mathrm{R} \& \mathrm{~W}$ eco-system, where a hospitable space is created characterised by service, integrity and honesty. In this particular case, the outcome of creating this flourishing environment was that each participant has been able to find their voice as a 
leader. They are now ready to serve and empower others. How many more voices might we hear if we were to adopt such an approach in other contexts and settings?

\section{References}

Baumfield, V., Hall, E., \& Wall, K. (2013). Action research in education: Learning through practioner enquiry. Sage.

Baumfield, V., Bethel, A., Brown, S., \& Walsh, K. (2021). Teachers as researchers: RE teachers' engagement with research. University of Exeter.

Commission on Religious Education. (2018) Religion and Worldviews: The Way Forward. A National Plan for RE. 2018 Religious Education Council of England and Wales, London.

Cooling, T., Bowie, R., \& Panjwani, F. (2020). Worldviews in religious education. Theos.

Details of the Culham St Gabriel's Leadership Programme can be found here: https://www.reonline.org.uk/ leadership/leadership-programme/

Hannam, P. (2016). What should religious education aim to achieve? An investigation into the purpose of religious education in the public sphere. University of Stirling.

King, M L. "I Have a Dream." Speech presented at the March on Washington for Jobs and Freedom, Washington, D.C., August 1968. Transcipt accessed: https://avalon.law.yale.edu/20th_century/mlk01.asp.

Moss, F. (1998). TT69: Learning from religion. Farmington Institute.

Orchard, J., Williams, A., Christopher, K., McKeown, S., Jackson-Royal, R., Wright, K., Wan, S.W.-Y., \& Davids, N. (2012). Knowledge exchange, intergroup relations and 'sharing space': A community of enquiry for the professional development of teachers of religion and worldviews. British Journal of Religious Education, 43(3), 265-277.

Wright, K. (2017). A pedagogy of embrace. A theology of hospitality as a pedagogical framework for church of England schools. University of East Anglia.

Publisher's Note Springer Nature remains neutral with regard to jurisdictional claims in published maps and institutional affiliations.

\section{Authors and Affiliations}

 Sean Whittle ${ }^{5}$}

Justine Ball

Justine.ball@hants.gov.uk

Claire Clinton

Claire.clinton@rematters.co.uk

Fiona Moss

fiona@ retoday.org.uk

Ed Pawson

efpawson@gmail.com

Sean Whittle

sean.whittle@stmarys.ac.uk

1 Culham St Gabriel's Trust, Oxford, UK

2 Hampshire, England

3 Newham, England

4 Birmingham, England

5 London, England 